\title{
Serological diagnosis of autoimmune bullous skin diseases: Prospective comparison of the BIOCHIP mosaic-based indirect immunofluorescence technique with the conventional multi-step single test strategy
}

Nina van Beek ${ }^{1}$, Kristin Rentzsch ${ }^{2}$, Christian Probst ${ }^{2}$, Lars Komorowski ${ }^{2}$, Michael Kasperkiewicz ${ }^{1}$, Kai Fechner ${ }^{2}$, Inga M Bloecker ${ }^{2}$, Detlef Zillikens ${ }^{1}$, Winfried Stöcker ${ }^{2}$ and Enno Schmidt ${ }^{1,3 *}$

\begin{abstract}
Background: Various antigen-specific immunoassays are available for the serological diagnosis of autoimmune bullous diseases. However, a spectrum of different tissue-based and monovalent antigen-specific assays is required to establish the diagnosis. BIOCHIP mosaics consisting of different antigen substrates allow polyvalent immunofluorescence (IF) tests and provide antibody profiles in a single incubation.

Methods: Slides for indirect IF were prepared, containing BIOCHIPS with the following test substrates in each reaction field: monkey esophagus, primate salt-split skin, antigen dots of tetrameric BP180-NC16A as well as desmoglein 1-, desmoglein 3-, and BP230gC-expressing human HEK293 cells. This BIOCHIP mosaic was probed using a large panel of sera from patients with pemphigus vulgaris ( $P V, n=65)$, pemphigus foliaceus $(P F, n=50)$, bullous pemphigoid (BP, $n=42)$, and non-inflammatory skin diseases $(n=97)$ as well as from healthy blood donors $(n=100)$. Furthermore, to evaluate the usability in routine diagnostics, 454 consecutive sera from patients with suspected immunobullous disorders were prospectively analyzed in parallel using a) the IF BIOCHIP mosaic and b) a panel of single antibody assays as commonly used by specialized centers.
\end{abstract}

Results: Using the BIOCHIP mosaic, sensitivities of the desmoglein 1-, desmoglein 3-, and NC16A-specific substrates were $90 \%, 98.5 \%$ and $100 \%$, respectively. BP230 was recognized by 54\% of the BP sera. Specificities ranged from $98.2 \%$ to $100 \%$ for all substrates. In the prospective study, a high agreement was found between the results obtained by the BIOCHIP mosaic and the single test panel for the diagnosis of BP, PV, PF, and sera without serum autoantibodies (Cohen's k between 0.88 and 0.97).

Conclusions: The BIOCHIP mosaic contains sensitive and specific substrates for the indirect IF diagnosis of BP, PF, and PV. Its diagnostic accuracy is comparable with the conventional multi-step approach. The highly standardized and practical BIOCHIP mosaic will facilitate the serological diagnosis of autoimmune blistering diseases.

\footnotetext{
* Correspondence: enno.schmidt@uk-sh.de

'Department of Dermatology, University of Luebeck, Luebeck, Germany ${ }^{3}$ Comprehensive Center for Inflammation Medicine (CCIM), University of Luebeck, Luebeck, Germany

Full list of author information is available at the end of the article
} 


\section{Background}

Autoimmune bullous disorders are characterized by autoantibodies against desmosomal proteins (in pemphigus), adhesion molecules of the dermal-epidermal junction (in pemphigoid diseases), and epidermal/ tissue transglutaminase (in dermatitis herpetiformis), respectively [1-3]. The most frequent autoimmune bullous diseases are bullous pemphigoid and pemphigus, with incidences varying considerably between geographical regions [4-8]. Incidences for BP range from 13.4- 42 new patients/ million inhabitants per year $[5,6,8,9]$. In a population aged 80 years and above the incidence of BP has been reported to be $150-190$ new patients/million/ year $[6,10]$. In central Europe, pemphigus is less frequent with incidences ranging from 0.6 to 6.8 new patients/ million/year $[5,8,11]$, higher incidences can be found in Southeastern Europe, the Mediterranean region, Iran and the Jewish population [7,12]. In pemphigoid gestationis and mucous membrane pemphigoid incidences of 2.0 patients/million/year were reported $[6,13]$. Incidences of the other entities are below 1.0/million/year.

Diagnosis relies on a combination of clinical features as well as the detection of skin-/ mucous membranebound and circulating autoantibodies [14,15]. The diagnostic gold standard is still the visualization of skin-/ mucous membrane-bound autoantibodies by direct immunofluorescence (IF) microscopy [16]. Advances in the identification of target antigens (summarized in Table 1) and the subsequent development of an increasing number of sensitive and specific assays for the detection of circulating autoantibodies, including Western blotting of cell-derived and recombinant forms of the target antigens, immunoprecipitation, and ELISA, allow serological diagnosis in the majority of patients [15]. Several ELISA systems using recombinant fragments of BP180, BP230, desmoglein 1, desmoglein 3, envoplakin, and type VII collagen have become commercially available and are highly valuable diagnostic tools (MBL, Nagoya, Japan and EUROIMMUN AG, Luebeck, Germany) [17-23].

Usually, the determination of serum autoantibodies is a multi-step procedure comprising an initial screening step by indirect IF microscopy using frozen sections of one or two tissues followed by more specific tests that aim at identifying the target antigen(s). Indirect IF microscopy on monkey esophagus (for pemphigus) and human skin, where the dermal-epidermal junction has been split by $1 \mathrm{M} \mathrm{NaCl}$ solution (for pemphigoid diseases), has been elucidated as the most sensitive screening tests [24-27]. The subsequent elaborate identification of the target antigen varies amongst different laboratories.

Here, to facilitate the serological diagnosis of immunobullous disorders, a multiplex IF BIOCHIP mosaic has been developed that combines screening and target antigen-specific substrates in a single miniature incubation field. Validation of the BIOCHIP showed high specificity and high sensitivity for pemphigus vulgaris (PV), pemphigus foliaceus (PF), and bullous pemphigoid (BP). In the second set of experiments, a large panel of consecutive sera from suspected autoimmune blistering disease patients sent to the Laboratory for Autoimmune Diagnostics of the Dermatology Department at the University of Luebeck was analysed with both the BIOCHIP mosaic and the conventional diagnostic multi-step algorithm.

\section{Methods \\ Patients}

For the validation of the novel BIOCHIP mosaic, sera from patients with BP $(n=42), P V(n=65)$, and PF $(n=50)$ were used. Patients were characterized by (i) the typical clinical phenotype, (ii) positive direct IF result, and (iii) serum autoantibodies against BP180 NC16A, desmoglein (Dsg) 3, and Dsg1, respectively. In addition, sera from patients with linear IgA dermatosis, non-inflammatory skin diseases (NISD), including vascular leg ulcers, basal cell carcinoma, and squamous cell carcinoma $(n=97)$, and healthy blood donors (HBD, $n=100$ ), were used. All sera were anonymized before testing. For the prospective comparative study, 454 consecutive sera from patients with suspected autoimmune bullous disease were analyzed independently by experienced staff members of the diagnostic laboratories of EUROIMMUN and the dermatology department, using both the BIOCHIP mosaic and the routine multi-step diagnostic algorithm. The study was approved by the local ethic committees (10-017).

In 9 patients (PV, $\mathrm{n}=3 ; \mathrm{PF}, \mathrm{n}=3 ; \mathrm{BP}, \mathrm{n}=3$ ), sera were analyzed during the course of the disease at 3-5 different time points. Disease activity for skin lesions: score of 4, >10 lesions; score of 3, 4 to 10 lesions; score of 2, 1 to 3 lesions; score of 1 , clinical remission on immunosuppressive therapy; score of 0 , clinical remission without immunosuppressive therapy) [28]. Scoring was done retrospectively based on photographs and patient records; serum was drawn on the same day when photographs were taken.

\section{BIOCHIP mosaic}

The membrane bound extracellular domains of Dsg1 (amino acids 1-569;) and Dsg3 (amino acids 1-640) were cloned as described [22] with the modification of using alternate antisense primers to include the respective coding regions for the transmembrane (TM) domains: CAA TGT CTG CAC ATA GCT CTA GGC GTC GAC TTA ATG ATG ATG ATG ATG AT (Dsg1) and ATA CTC GAG TTA ATG ATG ATG ATG ATG ATG GGT CAA CAG CAG AAG GGG GGC CAA C 
Table 1 Overview of target antigens in immunobullous diseases and diagnostic methods used in this study

\begin{tabular}{|c|c|c|}
\hline Disease & Target antigen & Routine multi-step approach ${ }^{1}$ \\
\hline Pemphigus vulgaris & Desmoglein 3 & Desmoglein 3 ELISA [22] \\
\hline Pemphigus foliaceus & Desmoglein 1 & Desmoglein 1 ELISA [22] \\
\hline \multirow[t]{4}{*}{ Paraneoplastic pemphigus } & Desmoglein 3 & Desmoglein 3 ELISA [22] \\
\hline & Envoplakin & Envoplakin ELISA [21] \\
\hline & Periplakin/ Desmoplakin I/II & Immunoblot with extract of cultured $\mathrm{HaCaT}$ cells [21] \\
\hline & & Indirect IF microscopy on rat and monkey bladder \\
\hline \multirow[t]{4}{*}{ Bullous pemphigoid } & BP180 & BP180 NC16A ELISA [20] \\
\hline & BP230 & BP230 ELISA [51] \\
\hline & Soluble ectodomain of BP180 (LAD-1) & BP180 4575 (c-terminal fragment) Immunoblot $[33,63]$ \\
\hline & & LAD-1 Immunoblot $[33,63]$ \\
\hline \multirow[t]{2}{*}{ Pemphigoid gestationis } & BP180 & BP180 NC16A ELISA [20] \\
\hline & & Complement binding test \\
\hline \multirow[t]{2}{*}{ Linear IgA dermatosis } & Soluble ectodomain of BP180 (LAD-1) & $\begin{array}{l}\text { Immunoblot with conditioned medium of cultured } \\
\mathrm{HaCaT} \text { cells (IgA reactivity) ) [33,63] }\end{array}$ \\
\hline & BP230 & BP230 ELISA [51] \\
\hline \multirow[t]{2}{*}{ Lichen planus pemphigoides } & BP180 & BP180 NC16A ELISA [51] \\
\hline & BP230 & BP230 ELISA [51] \\
\hline \multirow[t]{4}{*}{ Mucous membrane pemphigoid } & Soluble ectodomain of BP180 (LAD-1) & $\begin{array}{l}\text { Immunoblot with conditioned medium of cultured } \\
\mathrm{HaCaT} \text { cells (IgG and IgA reactivity) [33] }\end{array}$ \\
\hline & BP180 & BP180 NC16A ELISA [20] \\
\hline & BP230 & BP230 ELISA [51] \\
\hline & Laminin 332 & Immunoblot with extracellular matrix of cultured $\mathrm{HaCaT}$ cells $[13,35]$ \\
\hline \multirow[t]{2}{*}{ laminin $\gamma 1 /$ anti-p200 pemphigoid } & p200 protein/ Laminin $\gamma 1$ & Immunoblot with extract of human dermis [34] \\
\hline & & Immunoblot with recombinant laminin $\gamma 1$ C-term [37] \\
\hline Epidermolysis bullosa acquisita & Type VII collagen & Immunoblot with recombinant NC1-domain of type VII collagen [36] \\
\hline Dermatitis herpetiformis & Epidermal/tissue transglutaminase, gliadin & $\begin{array}{l}\text { Transglutaminase ELISA deamidated gliadin-analogous } \\
\text { fusion peptide-specific ELISA [32] }\end{array}$ \\
\hline
\end{tabular}

${ }^{1}$ in addition, all sera were subjected to indirect IF microscopy on human salt-split skin and monkey esophagus. The exact diagnostic algorithm applied in this study is detailed in [38].

IF, immunofluorescence; LAD-1, linear IgA dermatosis antigen 1(soluble ectodomain of BP180); BP180NC16A, targeted extracellular domain of BP180.

(Dsg3). The coding region for the C-terminal globular domain of BP230 (BP230gC; amino acids 1875-2649) was amplified from an EST cDNA (DKFZp686C04183Q, acc. no. BX475892, Imagene, Berlin, Germany) in two separate fragments to delete an intron using primer pairs ATA GTC GAC GCC ATG GAC TGT ACC TTC AAA CCA GAT TTT GAG and ATA TCG TCT CTA TCT CTA AGG GTG TCA AAA CCT TCA CC and ATA TCG TCT CAA GAT AGC TAA GAA CAA GCA GTA TG and ATA CTC GAG TAA GGA AGA ATA GTA GAG GC. The two BP230gC fragments are linked together, employing the unique BspHI site. The cDNAs were digested with the appropriate restriction enzymes and then ligated with linearized pTriEx-1 (Merck Biosciences, Darmstadt, Germany).

HEK293 cells (ATCC, CRL-1573) were cultivated and transfected with the pTriEx-1 constructs of Dsg1-TM, Dsg3-TM, and BP230gC as described [22] and seeded on cover slides. After cultivation for $48 \mathrm{hrs}$ at $37^{\circ} \mathrm{C}$, cells were fixed with formalin (Dsg) or acetone (BP230) for $10 \mathrm{~min}$ and stored in liquid nitrogen until further processing. Other cover glasses were coated with recombinant tetrameric NC16A (BP180-NC16A-4X), expressed as described previously [20], and with frozen tissue sections of monkey esophagus and primate $1 \mathrm{M} \mathrm{NaCl}$-split skin. Cover glasses were automatically cut into millimetersized fragments (BIOCHIPs) and glued side by side on microscopy slides, resulting in multiparametric BIOCHIP mosaics (Figure 1A) for simultaneous incubation of each serum sample on all substrates.

Slides containing the BIOCHIP mosaics were incubated with serial serum dilutions (starting with 1:10 in PBS-Tween) for $30 \mathrm{~min}$ at room temperature, rinsed with a flush of PBS-Tween and immersed in PBS-Tween for $5 \mathrm{~min}$. For detection of bound antibodies, fluorescein isothiocyanate (FITC)-conjugated goat anti-human IgA/G 


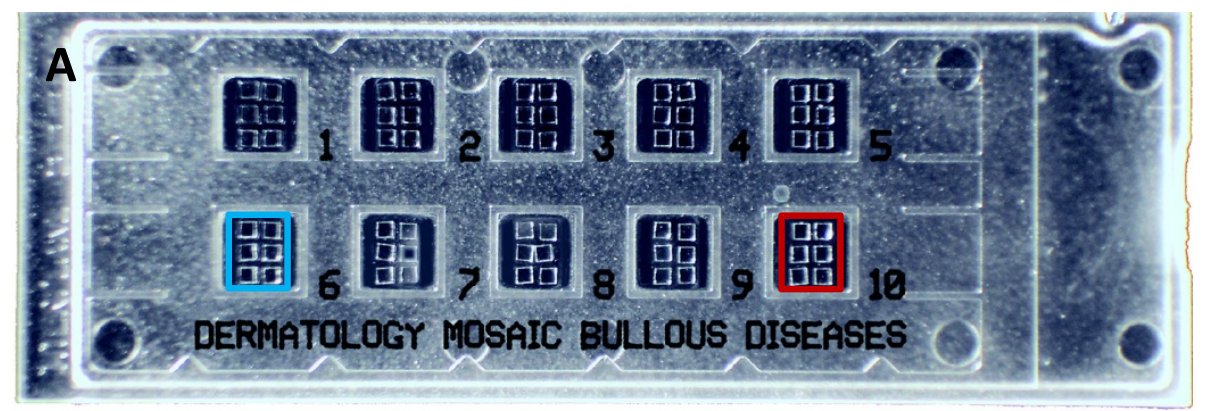

\section{B Bullous pemphigoid}

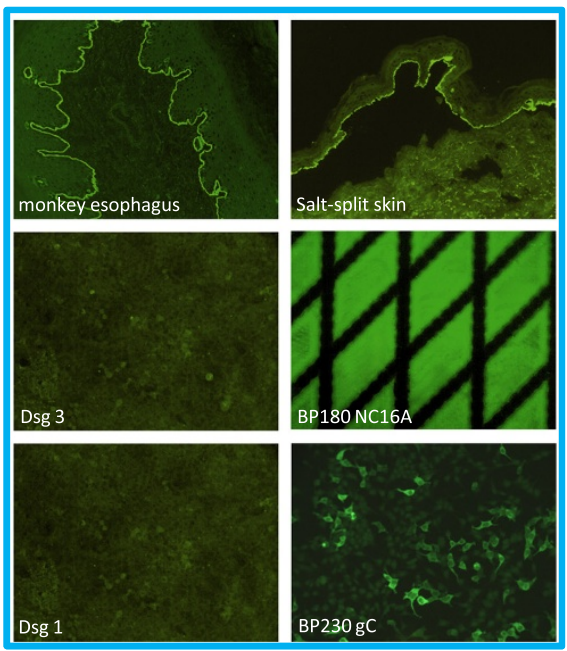

C Pemphigus vulgaris

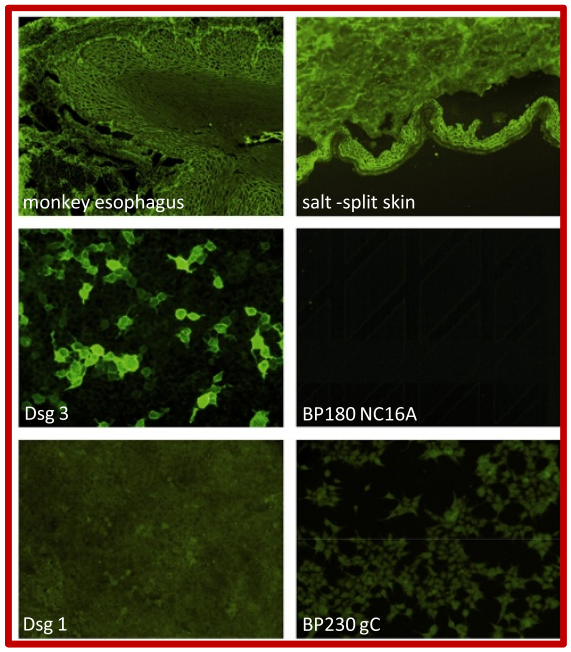

Figure 1 BIOCHIP mosaic for immunobullous disorders. (A) On a standard-sized slide, there are ten incubation fields each with six different BIOCHIPs. (B, C) Representative stainings after incubation with a bullous pemphigoid (B) and pemphigus vulgaris (C) serum. Desmoglein (Dsg) 1, Dsg3, and BP230gC (C-terminal globular domain of BP230) are expressed in human HEK293 cells. BP180 NC16A is directly coated on the BIOCHIP. HEK293 cells transfected with pTriEx-1 serve as negative control.

(EUROIMMUN) was applied for 30 minutes at room temperature, followed by washing as described before. The slides were then embedded using mounting medium (EUROIMMUN) and examined by fluorescence microscopy. Titer steps of 1:10, 1:32, 1:100, 1:320, 1:1000 and 1:3200 were obtained for correlation with disease activity in selected sera.

Diagnosis of BP was made based on reactivity with salt-split skin or monkey esophagus and reactivity with BP180 or BP230. In case of basal membrane zone staining without reactivity against BP180 or BP230 the diagnosis was "pemphigoid disease". When no reactivity was seen in any of the six biochips of one incubation field, a negative result was obtained.

\section{Multi-step serum analysis}

All samples were analyzed by experienced investigators using indirect IF microscopy on monkey esophagus and $1 \mathrm{M} \mathrm{NaCl}$-split human skin [26] for the detection of antihuman IgG and IgA secondary antibodies (both Bio-Rad, Munich, Germany) and a MicroImaging microscope
(Carl Zeiss, Jena, Germany). In case of suspected pemphigoid gestationis and paraneoplastic pemphigus, IF microscopy on salt-split human skin (complement binding [29]) and on rat/monkey bladder was performed, respectively. According to IF results and clinical suspicion, target antigen-specific assays were employed, including (i) Dsg 1-specific ELISA [22], (ii) Dsg 3-specific ELISA [22], (iii) BP180-specific ELISA [20,30], (iv) BP230-specific ELISA [19,31], (v) envoplakin-specific ELISA [21], (vi) transglutaminasespecific ELISA [32], (vii) deamidated gliadin-analogous fusion peptides-specific ELISA [32] (all EUROIMMUN; all performed following the manufacturer's instructions), (viii) immunoblotting (IB) with the soluble ectodomain of BP180 (LAD-1) in conditioned concentrated medium of cultured $\mathrm{HaCaT}$ [33], (ix) IB with dermal extract [34], (x) IB with cultured HaCaT cells [21], (xi) IB with the extracellular matrix of cultured HaCaT cells [35], (xii) IB with the recombinant $\mathrm{NC1}$-domian of type VII collagen [36], and (xiii) IB with the recombinant C-terminus of laminin $\gamma 1$ [37] (Table 1). In all sera with suspected BP, 
the BP180 NC16A ELISA was used. The exact diagnostic algorithm of the autoimmune laboratory, Department of Dermatology, University of Luebeck, applied in this study is detailed in [38].

Diagnosis was based on (i) a positive ELISA, (ii) a positive indirect IF in combination with a positive IB result, or (iii) positive results in 2 different IBs. A serum was evaluated as "negative" when all tests were unreactive or showed only a weak staining at a dilution of 1:10. For post hoc analysis of sera with discordant results compared to the BIOCHIP mosaic, additional analyses were performed, including Dsg 1-, Dsg 3-, BP180-, and BP230-specific ELISA (MBL) [17,19,30].

\section{Statistics}

To determine the sensitivity and specificity of the BIOCHIPs used in the evaluated mosaic, receiver operating curves (ROC) were analyzed. Confidence intervals, sensitivity and specificity were calculated using SigmaPlot 11.0 analysis software (SSI, San Jose, CA, USA). Cohen's Kappa was calculated with Gnu R open access software ( $\mathrm{R}$ Development Core Team 2009; R Foundation for Statistical Computing, Vienna, Austria, volume 2.13, package "irr") to evaluate the inter-rate analytical agreement between the BIOCHIP mosaic and the multi-step procedure [39]. $\kappa$ values of $0.41-0.60$ are rated as moderate concordance, $\mathrm{k}$ values of $0.61-0.80$ as substantial and of 0.81-1.00 almost perfect concordance [40]. Sera were anonymized before analysis.

\section{Results}

Validation of the BIOCHIP mosaic

Anti-basal membrane zone reactivity was seen in 41 of 42 BP sera (98.8\%). Antibodies against tetrameric BP180 $\mathrm{NC} 16 \mathrm{~A}$ and $\mathrm{BP} 230 \mathrm{gC}$ were found in $42(100 \%)$ and 23 (54.8\%) BP sera, respectively. Specificities were calculated to be $98.8 \%, 98.2 \%$, and $100 \%$ (Table 2). Staining of a representative BP serum is shown in Figure 1B.

Intercellular epithelial staining on monkey esophagus by indirect IF was observed in $65 \mathrm{PV}$ and $49 \mathrm{PF}$ sera resulting in sensitivities of $100 \%$ and $98.0 \%$, respectively. Anti-Dsg3 antibodies were detected in 64 of 65 (98.5\%) PV sera, in 34 (52.3\%) of these sera, additional anti-Dsg1 reactivity was found. Staining of a representative PV serum is shown in Figure 1C. Anti-Dsg1 reactivity was present in 45 of 50 (90\%) PF sera. Specificities for indirect IF microscopy on monkey esophagus, anti-Dsg1 reactivity, and anti-Dsg3 reactivity were $89.1 \%, 100 \%$, and $99.6 \%$, respectively (Table 3 ).

\section{Correlation of serum autoantibody levels with disease activity}

Sera of nine patients (BP, $\mathrm{n}=3 ; \mathrm{PF}, \mathrm{n}=3 ; \mathrm{PV}, \mathrm{n}=3$ ) taken during the course of the disease were analyzed by both
Table 2 Characteristics of pemphigoid disease-related substrates used in the BIOCHIP mosaic

\begin{tabular}{lcc}
\hline Disease & BP180-NC16A-4X & BP230gC \\
\hline Bullous pemphigoid & $\mathbf{4 2 / 4 2}$ & $\mathbf{2 3 / 4 2}$ \\
Sensitivity & $100 \%$ & $54.8 \%$ \\
$95 \% \mathrm{Cl}$ & $91.6-100 \%$ & $38.7-70.2 \%$ \\
Specificity & $98.2 \%$ & $100 \%$ \\
$95 \% \mathrm{Cl}$ & $96.7-99.3 \%$ & $98.9-100 \%$ \\
Pemphigus vulgaris & $\mathbf{0 / 6 5}$ & $\mathbf{0 / 6 5}$ \\
Pemphigus foliaceus & $\mathbf{0 / 5 0}$ & $\mathbf{0 / 5 0}$ \\
Linear IgA disease & $\mathbf{0 / 1 8}$ & $\mathbf{0 / 1 8}$ \\
HBD & $\mathbf{1 / 1 0 0}$ & $\mathbf{0 / 1 0 0}$ \\
NISD & $\mathbf{7 / 9 7}$ & $\mathbf{0 / 9 7}$
\end{tabular}

BP230gC, c-terminal globular domain of BP230; HBD, healthy blood donors; NISD, non-inflammatory skin diseases; $95 \% \mathrm{Cl}, 95 \%$ confidence intervals.

the BIOCHIP mosaic and conventional ELISA. IF titers by the novel biochip paralleled both ELISA values and disease activity (Figure 2).

\section{Prospective study on the diagnostic agreement between} the BIOCHIP mosaic and the conventional multi-step procedure

When the 454 consecutive sera from patients with suspected autoimmune blistering disease were subjected to both indirect IF with the BIOCHIP mosaic and the conventional multi-step procedure, concordant diagnoses were obtained in $425(93.6 \%)$ of sera ( $\kappa$ value of 0.88 ) (Figure 3). BP was diagnosed in $17.8 \%(\mathrm{n}=81)$, PV in $3.1 \%(n=14)$, and PF in $1.1 \%(n=5)$. In 322 sera $(70.9 \%)$,

Table 3 Characteristics of pemphigus-related substrates used in the BIOCHIP mosaic

\begin{tabular}{lcc}
\hline Disease & Desmoglein $\mathbf{1}$ & Desmoglein $\mathbf{3}$ \\
\hline Pemphigus vulgaris & $\mathbf{3 3 / 6 5}$ & $\mathbf{6 4 / 6 5}$ \\
Sensitivity & 52.3 & 98.5 \\
$95 \% \mathrm{Cl}$ & $39.5 \%$ to $64.9 \%$ & $91.7 \%$ to $100 \%$ \\
Specificity & 100 & $99.6 \%$ \\
$95 \% \mathrm{Cl}$ & $98.6 \%$ to $100 \%$ & $98.6 \%$ to $100 \%$ \\
Pemphigus foliaceus & $\mathbf{4 5 / 5 0}$ & $\mathbf{3 / 5 0}$ \\
Sensitivity \% & $90 \%$ & not applicable \\
$95 \% \mathrm{Cl}$ & $78.2 \%$ to $96.7 \%$ & \\
Specificity \% & $100 \%$ & $99.6 \%$ \\
$95 \% \mathrm{Cl}$ & $98.6 \%$ to $100 \%$ & $97.9 \%$ to $100 \%$ \\
Linear lgA disease & $\mathbf{0 / 1 8}$ & $\mathbf{0 / 1 8}$ \\
Bullous pemphigoid & $\mathbf{0 / 4 2}$ & $\mathbf{1 / 4 2}$ \\
HBD & $\mathbf{0 / 1 0 0}$ & $\mathbf{0 / 1 0 0}$ \\
NISD & $\mathbf{0 / 9 7}$ & $\mathbf{0 / 9 7}$ \\
\hline
\end{tabular}

HBD, healthy blood donors; NISD, non-inflammatory skin diseases; $95 \% \mathrm{Cl}, 95 \%$ confidence intervals. 
A

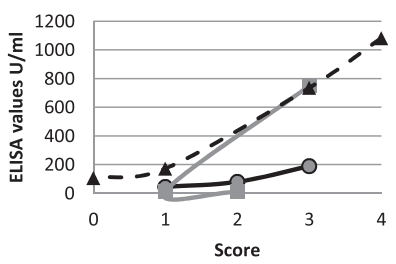

C

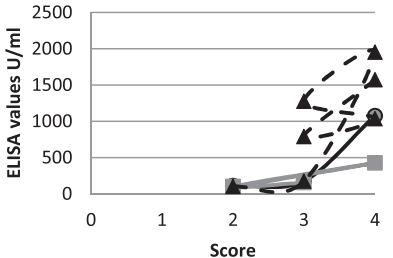

$\mathrm{E}$

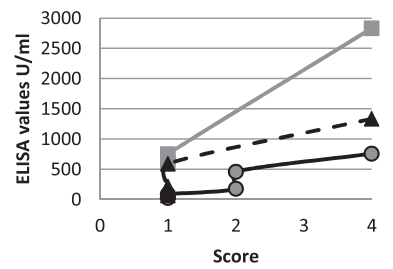

B
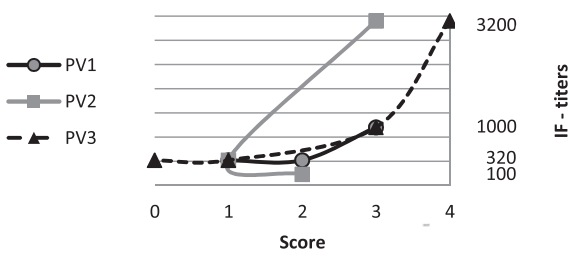

D

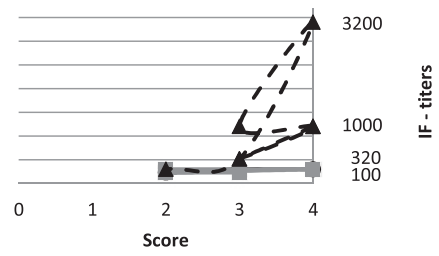

$\mathrm{F}$

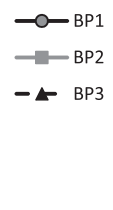

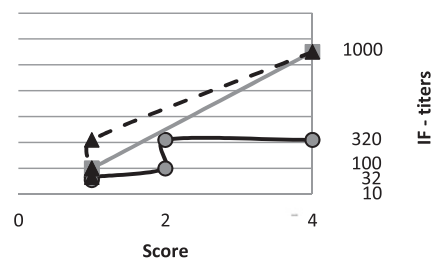

Figure 2 Correlation of serum autoantibody levels with disease activity. Values by conventional ELISA (Dsg3 (A), Dsg1 (C), BP180 (E)) paralleled indirect immunofluorescence titers by the BIOCHIP mosaic (Dsg3 (B), Dsg1 (D), BP180 (E)) obtained by testing sera from patients with pemphigus vulgaris (PV1-3) (A,B), pemphigus foliaceus (PF1-3) (C,D), and bullous pemphigoid (BP1-3) (E,F). Both ELISA values and indirect immunofluorescence titers appeared to correlate with disease activity determined by a clinical score (4, more than 10 lesions; 3, 4-10 lesions; 2, 1-3 lesions; 1, clinical remission on immunosuppressive therapy; 0 clinical remission without immunosuppressive therapy). Dsg, desmoglein; IF, immunofluorescence.

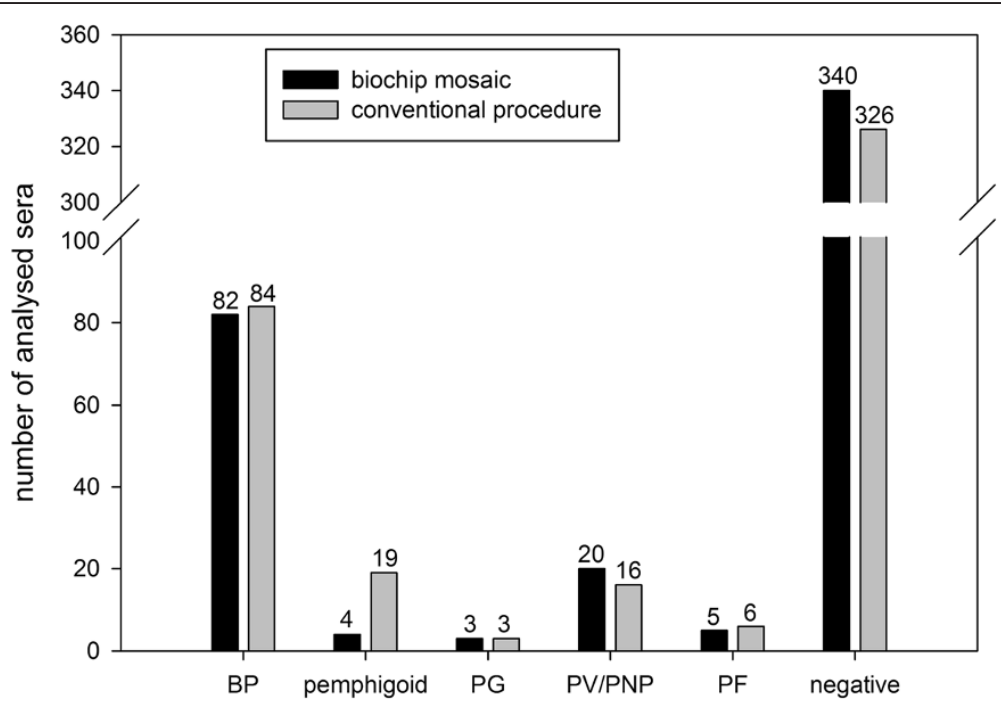

Figure 3 Evaluation of the BIOCHIP mosaic for the routine diagnosis of autoimmune bullous diseases. A large panel of consecutive sera $(n=453)$ from patients with suspected autoimmune bullous disease was subjected to both the BIOCHIP mosaic (black columns) and the routine multi-step procedures of the autoimmune laboratory of the department of dermatology, Luebeck (grey columns; detailed in [38]). Obtained diagnoses were grouped into BP (bullous pemphigoid), "pemphigoid" diseases (including linear lgA disease, p200-pemphigoid, mucous membrane pemphigoid and dermatitis herpetiformis), PV/PNP (pemphigus vulgaris/ paraneoplastic pemphigus), PF (pemphigus foliaceus), and PG (pemphigoid gestationis). PNP and "pemphigoid" sera are further specified in Table 4. 
no autoantibody reactivity was found. A high concordance for the diagnosis of $\mathrm{BP}, \mathrm{PV}, \mathrm{PF}$, and negative sera was found reflected by $\mathrm{K}$ values of $0.97,0.91$ and 0.88 , respectively (Figure 3). In 3 sera, both approaches resulted in the diagnosis of pemphigoid gestationis.

In a small portion of sera $(n=21 ; 4.6 \%)$, the conventional multi-step procedure identified additional disorders, including mucous membrane pemphigoid (MMP) $(n=6)$, linear IgA disease $(n=6)$, anti-p200 pemphigoid $(\mathrm{n}=5)$, dermatitis herpetiformis $(\mathrm{n}=2)$, and paraneoplastic pemphigus $(n=2)$. Four of these 21 sera, 2 with MMP, 1 with anti-p200 pemphigoid, and 1 with linear IgA disease, were diagnosed as "pemphigoid" by the BIOCHIP technique based on detection of autoantibodies against BP180 and positive staining on esophagus and/or salt-split skin (Figure 3). The exact results obtained with these sera are detailed in Table 4. After these primary analyses, incongruent results between the conventional multi-step procedure and the BIOCHIP mosaic, which were not explained by the different composition of the two approaches, were seen in $8(1.8 \%)$ sera. For these 8 sera, tests were repeated and appropriate additional analyses were performed, including MBL ELISAs. This post-hoc analysis resolved 5 discrepant results leaving incongruent analyses in $3(0.7 \%)$ sera (Table 4).

\section{Discussion}

The identification of target antigens in the great majority of autoimmune bullous diseases has led to the development of standardized specific and sensitive diagnostic assays, some of them have been commercialized [17,19-23,30,32,34-37,41-45] (Table 1). By the use of these assays, exact diagnosis can be made, which is of both prognostic and therapeutic relevance. Disease's prognosis may be greatly unfavorable in patients with paraneoplastic pemphigus [46] and anti-laminin-332 mucous membrane pemphigoid [47]. In addition, treatment of epidermolysis bullosa acquisita and pemphigus vulgaris is frequently challenging, while in linear IgA disease, anti-p200 pemphigoid, and in many patients with BP, complete remission can usually be achieved with relatively mild immunosuppression [48-50]. Target-specific diagnostic assays are usually applied in a multi-step approach, starting with a screening test for anti-desmosomal and anti-basal membrane zone antibodies using indirect IF microscopy on monkey esophagus and salt-split skin [15,24-26,38].

In the present study, a BIOCHIP mosaic was composed allowing the simultaneous detection of autoantibodies against the most frequent target antigens to facilitate the diagnosis of bullous skin diseases. Six different substrates were included: monkey esophagus, primate salt-split skin, recombinant BP180 NC16A-4X (antigen dots) and membrane-bound Dsg1 ectodomain, Dsg3 ectodomain, and the C-terminal globular domain of BP230. Additional substrates such as transitional epithelium and cells expressing the immunodominant portions of laminin 332, $\alpha 6 \beta 4$ integrin, and type VII collagen that would possibly have improved the detection of autoantibodies in paraneoplastic pemphigus (PNP), MMP, and epidermolysis bullosa acquisita, respectively, were not included due to the rarity of these disorders.

Validation of the BIOCHIP mosaic with sera from BP, PV, and PF patients revealed high sensitivities and

Table 4 Incongruent results obtained by the BIOCHIP mosaic and the conventional procedure

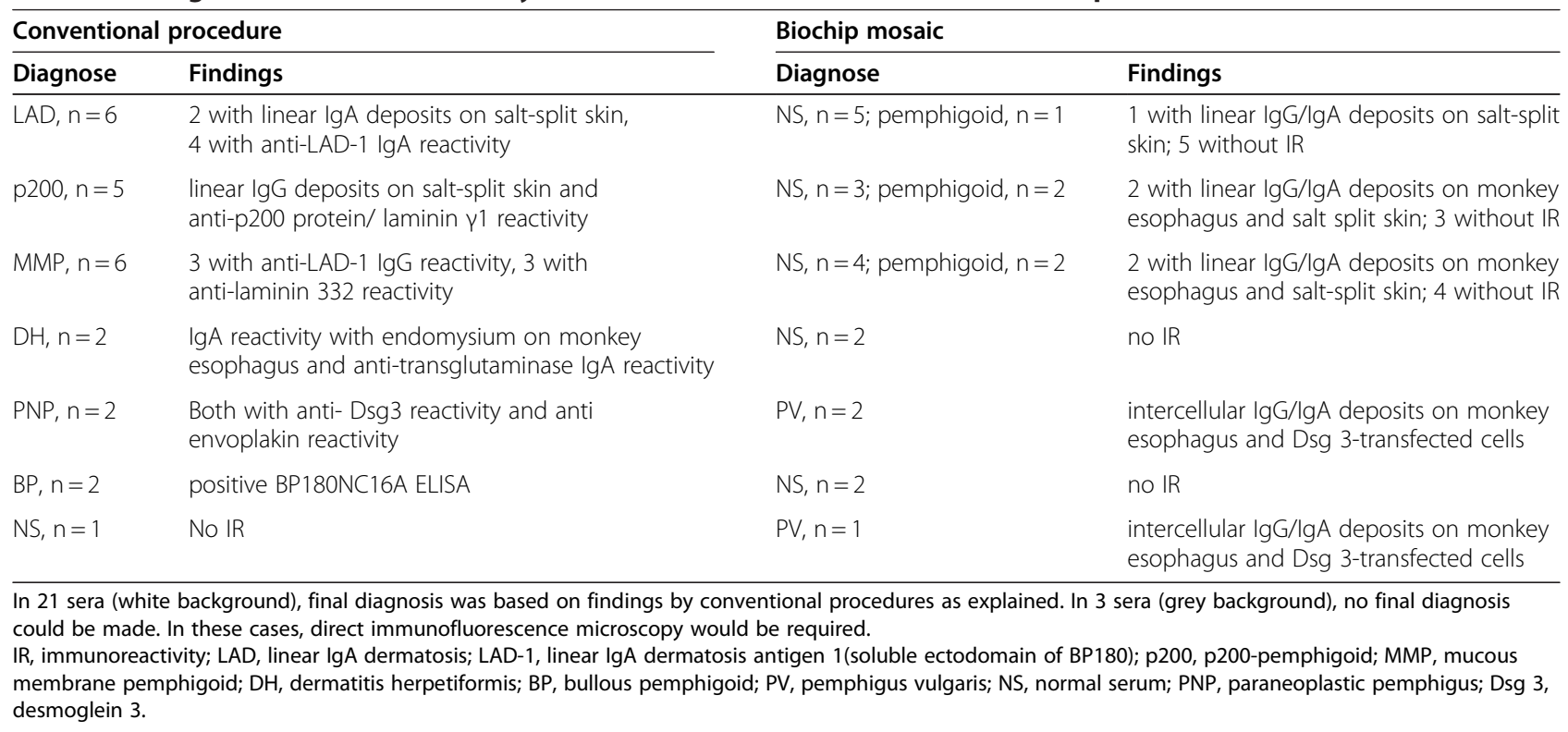


specificities comparable with those obtained by conventional approaches e.g. Dsg3 Elisa (97.5-100\% and 95.897.9\%), Dsg1 Elisa (96.0-97.9\% and 95.8-97.9\%) BP1 80NC16A Elisa (84.4-89.9\% and 97.8-98.9\%), and BP230 Elisa (63.0-72.4\% and 93-99.5\%) [17,19,20,22,30,51,52] (Tables 2 and 3). Previously, indirect IF microscopy of Sf21 insect cells expressing full-length BP180 has shown a sensitivity and specificity of $89 \%$ and $100 \%$, respectively, when probed with BP and control sera [53], however, this test is not widely available. The use of HEK293 cells results in the exclusive expression of the mature Dsg1 and Dsg3 forms, which have previously been shown to harbor major pathogenic epitopes on these two ectodomains $[54,55]$. Cells transfected with the corresponding "empty" plasmid serve as negative control substrates.

To explore the practical application of the BIOCHIP mosaic in the setting of a diagnostic routine laboratory, 454 consecutive sera from patients with suspected autoimmune blistering disease were probed independently using the novel BIOCHIP mosaic IF assay and the routine multi-step diagnostic approach. Results were compared only after the two sets of experiments were completed. High concordance with $\mathrm{K}$ values between 0.88 and 0.97 was observed for the diagnoses of BP, PV, $\mathrm{PF}$, and "negative".

As expected, the BIOCHIP mosaic did not exactly identify all entities. In fact, in only a small portion of sera $(3.7 \%)$, the BIOCHIP mosaic was unreactive, while the conventional multistep procedure revealed an autoimmune bullous disease, and in $0.9 \%$ of sera, pemphigoid diseases other than BP were detected. The reasons for this comprise the use of an anti-IgA/IgG secondary antibody and the lack of additional target antigens in the BIOCHIP mosaic. The anti-IgA/IgG secondary antibody allows the simultaneous detection of IgG and IgA antibodies which is practical and increases the sensitivity as most sera from patients with BP and MMP [33,56,57]) and many sera from patients with EBA contain IgA autoantibodies in addition to IgG reactivity [58]. However, this secondary antibody does not allow the diagnosis of linear IgA disease and dermatitis herpetiformis. For the diagnosis of anti-laminin 332 mucous membrane pemphigoid, anti-p200/ laminin $\gamma 1$ pemphigoid, epidermolysis bullosa acquisita, and paraneoplastic pemphigus additional target antigens need to be included in the BIOCHIP mosaic. The complementation of the BIOCHIP mosaic, which may be extended to up to $16 \mathrm{BIO}-$ CHIPs in one incubation field, with additional target antigens will, however, only be helpful in a small portion of sera $(<5 \%)$. In fact, meanwhile, an IF microscopybased assay employing the membrane-bound immunodominant NC1 domain of type VII collagen expressed in HEK293 cells has been shown as a highly sensitive and specific tool for the serological diagnosis of epidermolysis bullosa acquisita [36]. For the routine application of the current BIOCHIP mosaic we recommend the diagnostic pathway detailed in Additional file 1: Figure S1.

After the initial analysis, discordant results, which were not explained by the different composition of the BIOCHIP mosaic and the multi-step procedure, were seen in only $8(1.8 \%)$ sera. Following post hoc analysis, inconclusive results remained in $3(0.7 \%)$ sera. Since sera had been anonymized, direct IF microscopy could not be performed to clarify the discrepant results in these 3 sera.

It has previously been shown that the investigation of anti-BP230 reactivity in addition to BP180-specific antibodies is only of little diagnostic relevance [59-61]. Since all sera in our relatively small cohort of $42 \mathrm{BP}$ patients contained anti-BP180 antibodies, the diagnostic value of the $\mathrm{BP} 230 \mathrm{gC}$ BIOCHIP containing the entire globular C-terminal domain of BP230 could not be assessed. In $\mathrm{BP}, \mathrm{PV}$, and PF, autoantibody serum levels were shown to correlate with disease activity $[18,62]$. Monitoring of serum autoantibody levels during the course of disease may therefore be helpful in the treatment of patients. For the monitoring of autoantibody levels, the available ELISA kits appear to be more convenient than the novel BIOCHIP mosaic.

\section{Conclusions}

BIOCHIP mosaic-based indirect IF technique is useful in screening autoantibodies for routine diagnosis of BP, PV, and PF. Results are concordant compared with the routine multi-step diagnostic procedure. This simple, standardized, and readily available novel tool will further facilitate the diagnosis of autoimmune bullous diseases.

\section{Additional file}

Additional file 1: Figure S1. Proposed diagnostic pathway following analysis by the BIOCHIP mosaic. LAD-1, linear IgA dermatosis antigen 1 (soluble ectodomain of BP180).

\section{Abbreviations}

BP: Bullous pemphigoid; IF: Immunofluorescence; PF: Pemphigus foliaceus; PV: Pemphigus vulgaris; Dsg: Desmoglein; ELISA: Enzyme linked immunosorbant assay.

\section{Competing interests}

E.S. and D.Z. have a scientific collaboration with EUROIMMUN. K.R., C.P., L.K. K.F., and I-M.B are employed at EUROIMMUN. W.St. is president of EUROIMMUN and principal shareholder. N.VB. and M.K. declared no conflict of interest.

\section{Authors' contributions}

N.vB. and E.S. analyzed the data and wrote the manuscript. K.R. and IM.B. performed and supervised the BIOCHIP analyses. C.P., L.K., K.F., and W.St. developed the BIOCHIP mosaic technology and drafted the study. M.K. partially performed and supervised the routine multi-step analyses. W.St. and D.Z. advised on the experimental design of the study and revised the manuscript. All authors read and approved the final manuscript. 


\section{Acknowledgements}

This work was supported by the Excellence Cluster Inflammation at Interfaces (DFG 306/01). We thank Ingeborg Atefi, Marina Kongsbak-Reim, Vanessa Krull, Bianca Mathern, Beatrice Schneider, Sabrina Voigt, and Doreen Weigel for their excellent technical assistance.

\section{Author details}

'Department of Dermatology, University of Luebeck, Luebeck, Germany.

${ }^{2}$ Institute of Experimental Immunology, EUROIMMUN AG, Luebeck, Germany.

${ }^{3}$ Comprehensive Center for Inflammation Medicine (CCIM), University of

Luebeck, Luebeck, Germany.

Received: 7 March 2012 Accepted: 2 August 2012

Published: 9 August 2012

\section{References}

1. Eming R, Hertl M: Autoimmune bullous disorders. Clin Chem Lab Med 2006, 44:144-149

2. Sardy M, Karpati S, Merkl B, Paulsson M, Smyth N: Epidermal transglutaminase (TGase 3 ) is the autoantigen of dermatitis herpetiformis. J Exp Med 2002, 195:747-757.

3. Schmidt E, Zillikens D: The diagnosis and treatment of autoimmune blistering skin diseases. Dtsch Arztebl Int 2011, 108:399-405. I-III.

4. Kanwar AJ, De D: Pemphigus in India. Indian J Dermatol Venereol Leprol 2011, 77:439-449.

5. Marazza G, Pham HC, Scharer L, Pedrazzetti PP, Hunziker T, Trueb RM, Hohl D, Itin P, Lautenschlager S, Naldi L, Borradori L: Incidence of bullous pemphigoid and pemphigus in Switzerland: a 2-year prospective study. Br J Dermatol 2009, 161:861-868.

6. Bertram F, Brocker EB, Zillikens D, Schmidt E: Prospective analysis of the incidence of autoimmune bullous disorders in Lower Franconia, Germany. J Dtsch Dermatol Ges 2009, 7:434-440.

7. Chams-Davatchi C: Prevalence and treatment of pemphigus in Iran. Dermatol Clin 2011, 29:681-683.

8. Langan SM, Smeeth L, Hubbard R, Fleming KM, Smith CJ, West J: Bullous pemphigoid and pemphigus vulgaris-incidence and mortality in the UK: population based cohort study. BMJ 2008, 337:a180

9. Joly P, Baricault S, Sparsa A, Bernard P, Bedane C, Duvert-Lehembre S, Courville P, Bravard P, Remond B, Doffoel-Hantz V, Benichou J: Incidence and Mortality of Bullous Pemphigoid in France. J Invest Dermatol 2012, 132:1998-2004.

10. Jung M, Kippes W, Messer G, Zillikens D, Rzany B: Increased risk of bullous pemphigoid in male and very old patients: A population-based study on incidence. J Am Acad Dermatol 1999, 41:266-268.

11. Hahn-Ristic K, Rzany B, Amagai M, Brocker EB, Zillikens D: Increased incidence of pemphigus vulgaris in southern Europeans living in Germany compared with native Germans. J Eur Acad Dermatol Venereol 2002, 16:68-71.

12. Baican A, Baican C, Chiriac G, Chiriac MT, Macovei V, Zillikens D, Ciuce D, Sitaru C: Pemphigus vulgaris is the most common autoimmune bullous disease in Northwestern Romania. Int J Dermatol 2010, 49:768-774.

13. Chan LS, Ahmed AR, Anhalt GJ, Bernauer W, Cooper KD, Elder MJ, Fine JD, Foster CS, Ghohestani R, Hashimoto T, et al: The first international consensus on mucous membrane pemphigoid: definition, diagnostic criteria, pathogenic factors, medical treatment, and prognostic indicators. Arch Dermatol 2002, 138:370-379.

14. Mutasim DF, Adams BB: Immunofluorescence in dermatology. J Am Acad Dermatol 2001, 45:803-822.

15. Schmidt E, Zillikens D: Modern diagnosis of autoimmune blistering skin diseases. Autoimmun Rev 2010, 10:84-89.

16. Pohla-Gubo G, Kraus L, Hintner H: Role of immunofluorescence microscopy in dermatology. $G$ Ital Dermatol Venereol 2011, 146:127-142.

17. Ishii K, Amagai M, Hall RP, Hashimoto T, Takayanagi A, Gamou S, Shimizu N, Nishikawa T: Characterization of autoantibodies in pemphigus using antigen-specific enzyme-linked immunosorbent assays with baculovirusexpressed recombinant desmogleins. J Immunol 1997, 159:2010-2017.

18. Harman KE, Seed PT, Gratian MJ, Bhogal BS, Challacombe SJ, Black MM: The severity of cutaneous and oral pemphigus is related to desmoglein 1 and 3 antibody levels. Br J Dermatol 2001, 144:775-780.

19. Yoshida M, Hamada T, Amagai M, Hashimoto K, Uehara R, Yamaguchi K, Imamura K, Okamoto E, Yasumoto S, Hashimoto T: Enzyme-linked immunosorbent assay using bacterial recombinant proteins of human BP230 as a diagnostic tool for bullous pemphigoid. J Dermatol Sci 2006, 41:21-30.

20. Sitaru C, Dahnrich C, Probst C, Komorowski L, Blocker I, Schmidt E, Schlumberger W, Rose C, Stöcker W, Zillikens D: Enzyme-linked immunosorbent assay using multimers of the 16th non-collagenous domain of the BP180 antigen for sensitive and specific detection of pemphigoid autoantibodies. Exp Dermatol 2007, 16:770-777.

21. Probst C, Schlumberger W, Stöcker W, Recke A, Schmidt E, Hashimoto T, Zhu XJ, Zillikens D, Komorowski L: Development of ELISA for the specific determination of autoantibodies against envoplakin and periplakin in paraneoplastic pemphigus. Clin Chim Acta 2009, 410:13-18.

22. Schmidt E, Dahnrich C, Rosemann A, Probst C, Komorowski L, Saschenbrecker S, Schlumberger W, Stocker W, Hashimoto T, Brocker EB, et al: Novel ELISA systems for antibodies to desmoglein 1 and 3: correlation of disease activity with serum autoantibody levels in individual pemphigus patients. Exp Dermatol 2010, 19:458-463.

23. Saleh MA, Ishii K, Kim YJ, Murakami A, Ishii N, Hashimoto T, Schmidt E, Zillikens D, Shirakata Y, Hashimoto K, et al: Development of NC1 and NC2 domains of type VII collagen ELISA for the diagnosis and analysis of the time course of epidermolysis bullosa acquisita patients. J Dermatol Sci 2011, 62:169-175

24. Sabolinski ML, Beutner EH, Krasny S, Kumar V, Huang J, Chorzelski TP, Sampaio S, Bystryn JC: Substrate specificity of anti-epithelial antibodies of pemphigus vulgaris and pemphigus foliaceus sera in immunofluorescence tests on monkey and guinea pig esophagus sections. J Invest Dermatol 1987, 88:545-549.

25. Gammon WR, Kowalewski C, Chorzelski TP, Kumar V, Briggaman RA, Beutner EH: Direct immunofluorescence studies of sodium chloride-separated skin in the differential diagnosis of bullous pemphigoid and epidermolysis bullosa acquisita. J Am Acad Dermatol 1990, 22:664-670

26. Ghohestani RF, Nicolas JF, Rousselle P, Claudy AL: Diagnostic value of indirect immunofluorescence on sodium chloride-split skin in differential diagnosis of subepidermal autoimmune bullous dermatoses. Arch Dermatol 1997, 133:1102-1107.

27. Jiao D, Bystryn JC: Sensitivity of indirect immunofluorescence, substrate specificity, and immunoblotting in the diagnosis of pemphigus. J Am Acad Dermatol 1997, 37:211-216.

28. Schmidt E, Goebeler M, Zillikens D: Rituximab in severe pemphigus. Ann N Y Acad Sci 2009, 1173:683-691.

29. Sitaru C, Powell J, Shimanovich I, Jainta S, Kirtschig G, Wojnarowska F, Zillikens D: Pemphigoid gestationis: maternal sera recognize epitopes restricted to the $\mathrm{N}$-terminal portion of the extracellular domain of BP180 not present on its shed ectodomain. Br J Dermatol 2003, 149:420-422.

30. Kobayashi M, Amagai M, Kuroda-Kinoshita K, Hashimoto T, Shirakata Y, Hashimoto K, Nishikawa T: BP180 ELISA using bacterial recombinant NC16a protein as a diagnostic and monitoring tool for bullous pemphigoid. J Dermatol Sci 2002, 30:224-232.

31. Kromminga A, Sitaru C, Hagel C, Herzog S, Zillikens D: Development of an ELISA for the detection of autoantibodies to BP230. Clin Immunol 2004, 111:146-152

32. Kasperkiewicz M, Dahnrich C, Probst C, Komorowski L, Stocker W, Schlumberger W, Zillikens D, Rose C: Novel assay for detecting celiac disease-associated autoantibodies in dermatitis herpetiformis using deamidated gliadin-analogous fusion peptides. J Am Acad Dermatol 2011, 66:583-588.

33. Schmidt E, Skrobek C, Kromminga A, Hashimoto T, Messer G, Brocker EB, Yancey KB, Zillikens D: Cicatricial pemphigoid: IgA and IgG autoantibodies target epitopes on both intra- and extracellular domains of bullous pemphigoid antigen 180. Br J Dermatol 2001, 145:778-783.

34. Zillikens D, Kawahara Y, Ishiko A, Shimizu H, Mayer J, Rank CV, Liu Z, Giudice GJ, Tran HH, Marinkovich MP, et al: A novel subepidermal blistering disease with autoantibodies to a 200-kDa antigen of the basement membrane zone. J Invest Dermatol 1996, 106:1333-1338.

35. Lazarova Z, Sitaru C, Zillikens D, Yancey KB: Comparative analysis of methods for detection of anti-laminin 5 autoantibodies in patients with anti-epiligrin cicatricial pemphigoid. J Am Acad Dermatol 2004, 51:886-892.

36. Komorowski L, Müller R, Vorobyev A, Probst C, Recke A, Jonkman MF, Hashimoto T, Kim S-C, Groves R, Ludwig RJ, et al: Sensitive and specific assays for routine serological diagnosis of epidermolysis bullosa acquisita. J Am Acad Dermatol 2012, Epub ahead of print. 
37. Groth S, Recke A, Vafia K, Ludwig RJ, Hashimoto T, Zillikens D, Schmidt E: Development of a simple enzyme-linked immunosorbent assay for the detection of autoantibodies in anti-p200 pemphigoid. Br J Dermatol 2011, 164:76-82

38. Schmidt E, Zillikens D: Diagnosis and treatment of patients with autoimmune bullous disorders in Germany. Dermatol Clin 2011, 29:663-671.

39. Cohen J: A coefficient of agreement for nominal scales. Educational and Psychological Measurements 1960, 20:37-46.

40. Landis JR, Koch GG: The measurement of observer agreement for categorical data. Biometrics 1977, 33:159-174.

41. Csorba K, Schmidt S, Florea F, Ishii N, Hashimoto T, Hertl M, Karpati S, Bruckner-Tuderman L, Nishie W, Sitaru C: Development of an ELISA for sensitive and specific detection of IgA autoantibodies against BP180 in pemphigoid diseases. Orphanet J Rare Dis 2011, 6:31.

42. Dainichi T, Kurono S, Ohyama B, Ishii N, Sanzen N, Hayashi M, Shimono C, Taniguchi $Y$, Koga H, Karashima T, et al: Anti-laminin gamma-1 pemphigoid. PNAS 2008, 106:2800-2805.

43. Schepens I, Jaunin F, Begre N, Laderach U, Marcus K, Hashimoto T, Favre B, Borradori L: The protease inhibitor alpha-2-macroglobulin-like-1 is the p170 antigen recognized by paraneoplastic pemphigus autoantibodies in human. PLoS One 2010, 5:e12250.

44. Grootenboer-Mignot S, Descamps V, Picard-Dahan C, Nicaise-Roland P, Prost-Squarcioni C, Leroux-Villet C, Champagnat C, Delaval A, Aucouturier F, Crickx B, Chollet-Martin S: Place of human amniotic membrane immunoblotting in the diagnosis of autoimmune bullous dermatoses. Br J Dermatol 2010, 162:743-750.

45. Lee CW: An extract of cultured A431 cells contains major tissue antigens of autoimmune bullous diseases. Br J Dermatol 2000, 143:821-823.

46. Anhalt GJ, Kim SC, Stanley JR, Korman NJ, Jabs DA, Kory M, Izumi H, Ratrie H 3rd, Mutasim D, Ariss-Abdo L, et al: Paraneoplastic pemphigus. An autoimmune mucocutaneous disease associated with neoplasia. $N$ Engl J Med 1990, 323:1729-1735.

47. Egan CA, Lazarova Z, Darling TN, Yee C, Cote T, Yancey KB: Anti-epiligrin cicatricial pemphigoid and relative risk for cancer. Lancet 2001, 357:1850-1851.

48. Kirtschig G, Murrell D, Wojnarowska F, Khumalo N: Interventions for mucous membrane pemphigoid/cicatricial pemphigoid and epidermolysis bullosa acquisita: a systematic literature review. Arch Dermatol 2002, 138:380-384.

49. Martin LK, Werth VP, Villaneuva EV, Murrell DF: A systematic review of randomized controlled trials for pemphigus vulgaris and pemphigus foliaceus. J Am Acad Dermatol 2011, 64:903-908.

50. Joly P, Roujeau JC, Benichou J, Delaporte E, D'Incan M, Dreno B, Bedane C, Sparsa A, Gorin I, Picard C, et al: A comparison of two regimens of topical corticosteroids in the treatment of patients with bullous pemphigoid: a multicenter randomized study. J Invest Dermato/ 2009, 129:1681-1687.

51. Blocker IM, Dahnrich C, Probst C, Komorowski L, Saschenbrecker S, Schlumberger W, Stocker W, Zillikens D, Schmidt E: Epitope mapping of BP230 leading to a novel enzyme-linked immunosorbent assay for autoantibodies in bullous pemphigoid. Br J Dermatol 2012, 166:964-970.

52. Charneux J, Lorin J, Vitry F, Antonicelli F, Reguiai Z, Barbe C, Tabary T, Grange F, Bernard P: Usefulness of BP230 and BP180-NC16a enzymelinked immunosorbent assays in the initial diagnosis of bullous pemphigoid: a retrospective study of 138 patients. Arch Dermatol 2011, 147:286-291.

53. Schmidt E, Kromminga A, Mimietz S, Leinfelder U, Sitaru C, Brocker EB, Zillikens $D$, Zimmermann U: A highly sensitive and simple assay for the detection of circulating autoantibodies against full-length bullous pemphigoid antigen 180. J Autoimmun 2002, 18:299-309.

54. Sharma PM, Choi EJ, Kuroda K, Hachiya T, Ishii K, Payne AS: Pathogenic anti-desmoglein MAbs show variable ELISA activity because of preferential binding of mature versus proprotein isoforms of desmoglein 3. J Invest Dermatol 2009, 129:2309-2312.

55. Yokouchi M, Saleh MA, Kuroda K, Hachiya T, Stanley JR, Amagai M, Ishii K Pathogenic epitopes of autoantibodies in pemphigus reside in the amino terminal adhesive region of desmogleins which are unmasked by proteolytic processing of prosequence. J Invest Dermatol 2009, 129:2156-2166.

56. Kromminga A, Scheckenbach C, Georgi M, Hagel C, Arndt R, Christophers E, Brocker EB, Zillikens D: Patients with bullous pemphigoid and linear $\lg A$ disease show a dual $\lg A$ and $\lg G$ autoimmune response to BP180. J Autoimmun 2000, 15:293-300.
57. Christophoridis S, Budinger L, Borradori L, Hunziker T, Merk HF, Hertl M: IgG, $\lg \mathrm{A}$ and $\lg \mathrm{E}$ autoantibodies against the ectodomain of BP180 in patients with bullous and cicatricial pemphigoid and linear $\lg A$ bullous dermatosis. Br J Dermatol 2000, 143:349-355.

58. Buijsrogge JJ, Diercks GF, Pas HH, Jonkman MF: The many faces of epidermolysis bullosa acquisita after serration pattern analysis by direct immunofluorescence microscopy. Br J Dermatol 2011, 165:92-98.

59. Di Zenzo G, Thoma-Uszynski S, Fontao L, Calabresi V, Hofmann SC, Hellmark T, Sebbag N, Pedicelli C, Sera F, Lacour JP, et al: Multicenter prospective study of the humoral autoimmune response in bullous pemphigoid. Clin Immunol 2008, 128:415-426.

60. Roussel A, Benichou J, Randriamanantany ZA, Gilbert D, Drenovska K, Houivet $E$, Tron F, Joly P: Enzyme-linked immunosorbent assay for the combination of bullous pemphigoid antigens 1 and 2 in the diagnosis of bullous pemphigoid. Arch Dermatol 2011, 147:293-298.

61. Charneux J, Lorin J, Vitry F, Antonicelli F, Reguiai Z, Barbe C, Tabary T, Grange F, Bernard P: Usefulness of BP230 and BP180-NC16a enzymelinked immunosorbent assays in the initial diagnosis of bullous pemphigoid: a retrospective study of 138 patients. Arch Dermatol 2011, 147:286-291.

62. Schmidt E, Obe K, Brocker EB, Zillikens D: Serum levels of autoantibodies to BP180 correlate with disease activity in patients with bullous pemphigoid. Arch Dermatol 2000, 136:174-178.

63. Venning VA: Linear IgA disease: clinical presentation, diagnosis, and pathogenesis. Dermatol Clin 2011, 29:453-458. ix.

doi:10.1186/1750-1172-7-49

Cite this article as: van Beek et al:: Serological diagnosis of autoimmune bullous skin diseases: Prospective comparison of the BIOCHIP mosaicbased indirect immunofluorescence technique with the conventional multi-step single test strategy. Orphanet Journal of Rare Diseases 2012 7:49.

\section{Submit your next manuscript to BioMed Central and take full advantage of:}

- Convenient online submission

- Thorough peer review

- No space constraints or color figure charges

- Immediate publication on acceptance

- Inclusion in PubMed, CAS, Scopus and Google Scholar

- Research which is freely available for redistribution 